\title{
The Texas Earth and Space Science (TXESS) Revolution: A Model for the Delivery of Earth Science Professional Development to Minority-Serving Teachers
}

\author{
K. K. Ellins, ${ }^{1, a}$ E. Snow,${ }^{2}$ H. C. Olson, ${ }^{1}$ E. Stocks, ${ }^{3}$ M. Willis, ${ }^{4}$ J. Olson, ${ }^{5}$ and M. R. Odell ${ }^{6}$
}

\begin{abstract}
The Texas Earth and Space Science (TXESS) Revolution was a 5-y teacher professional development project that aimed to increase teachers' content knowledge in Earth science and preparing them to teach a 12th-grade capstone Earth and Space Science course, which is new to the Texas curriculum. The National Science Foundation-supported project was designed around six principles that proved to be critical to in its success: (1) model best practices in workshop presentations, (2) use authentic Earth science data and cybertechnology to teach up-to-date content, (3) provide ongoing training to cohorts of learners over a 2-y period, (4) involve geoscience consortia and programs that can provide proven content for classrooms, (5) use ongoing evaluations to guide future workshops, and (6) provide opportunities for leadership development through participation in research and curriculum development projects. The project served 177 science teachers by supporting them with the pedagogical, technological, and scientific tools to teach modern geoscience. TXESS Revolution teachers directly impacted more than 29,000 students, of which about $69 \%$ are nonwhite, by exposing students in Texas to the geosciences and planting the seeds for them to pursue geoscience as a field of study. Using a train-the-trainer approach, TXESS Revolution teachers shared their professional development with other Texas teachers, strengthening Earth science education at all K-12 levels throughout the state, an impact that extends beyond preparation in Earth and space science. (C) 2013 National Association of Geoscience Teachers. [DOI: 10.5408/12-348.1]
\end{abstract}

Key words: teacher professional development, diversity, Earth science, secondary education

\section{INTRODUCTION}

In 2006, changes to the Texas State Science curriculum, combined with a growing national concern for the future geoscience workforce, created a perfect storm of opportunity to implement a statewide teacher professional development program in Earth science education. A decade earlier, Texas had removed Earth science from the graduation requirements in Texas high schools (Roy, 2002), and geoscientists fought hard to reinstate it into the state curriculum. They succeeded, and when the new fourth-year science requirement was approved, Earth and Space Science was added as an optional capstone course for high school seniors. In support of the new requirement, the University of Texas at Austin's Institute for Geophysics (UTIG) launched a teacher-

Received 31 July 2012; revised 21 January 2013; accepted 31 January 2013; published online 14 May 2013.

${ }^{1}$ The Institute for Geophysics, Jackson School of Geosciences, The University of Texas at Austin, PRC Campus, 10100 Burnet Road, Austin, Texas 78758-4445, USA

${ }^{2}$ Jackson School of Geosciences, The University of Texas at Austin, PRC Campus, 10100 Burnet Rd., Bldg. 196, Austin, TX 78758-4445, USA

${ }^{3}$ Department of Psychology, The University of Texas at Tyler, HPR 223,

3900 University Blvd., Tyler, TX 75799, USA

${ }^{4}$ The Texas Regional Collaboratives for Excellence in Science and Mathematics Teaching, The University of Texas at Austin, Center for STEM Education, George I. Sánchez Bldg., 1912 Speedway, Austin, TX 78712-1608, USA

${ }^{5}$ Department of Petroleum and Geosystems Engineering, The University of Texas at Austin, 200 E. Dean Keeton, CPE 2.502, Austin, TX 787121587, USA

${ }^{6}$ Office of Sponsored Projects, The University of Texas at Tyler, ADM 362, 3900 University Blvd., Tyler, TX 75799, USA

${ }^{a}$ Author to whom correspondence should be addressed. Electronic mail: kellins@ig.utexas.edu. Tel.: 512-471-0347. Fax: 512-471-0319 training program called Texas Earth and Space Science (TXESS) Revolution. This article describes our experiences implementing this program between 2007 and 2012.

The TXESS Revolution, named with a nod toward the national Earth Science Revolution (Barstow and Geary, 2002), is a 5-y program in teacher professional development that engages teachers for a full $2 \mathrm{y}$. Sponsored by the National Science Foundation (NSF), the program uses authentic data and hands-on discovery to teach Earth science to teachers so that they, in turn, can teach it well to students. This initiative is particularly important in Texas, not only because of the large economic and environmental impact of geosciences on our state, but also because of the large and growing minority population.

The most rapidly growing segments of the U.S. population are largely underrepresented in science and engineering (National Academy of Science, 2010). The situation is particularly acute in the geosciences, which award fewer bachelor's and master's degrees to Hispanic, black, and American Indian/Native Alaskan students (collectively referred to as underrepresented minorities, or URMs) than are awarded in other science and engineering fields. Between 2000 and 2008, URMs were awarded only $5 \%$ to $7 \%$ of all geoscience degrees (NSF, 2010; O'Connell and Holmes, 2011); during the same period, URMs earned only $4 \%$ of geoscience doctoral degrees (Hallar et al., 2010; National Academy of Science, 2010; O'Connell and Holmes, 2011). These statistics, examined in the context of a projected workforce need of between 145,000 and 202,000 unfilled geoscience jobs by 2021 (American Geosciences Institute, 2011), have made broadening diversity in the geosciences a national imperative. 
In Texas, $66 \%$ of students are from demographic groups underrepresented in science, technology, engineering, and mathematics (STEM) disciplines (Texas Education Agency, 2010). Efforts in the state to broaden diversity and improve Earth science teacher preparation are mutually reinforcing and have the potential to strengthen the pathways oriented toward a geoscience workforce that is representative of the nation. Hispanics represent a major portion of the Texas population-37.6\% of the state overall and $90 \%$ of South Texas-yet they remain vastly underrepresented in the hightech workforce and scientific community (U.S. Census Bureau, 2010). Contributing factors include the lower high school graduation rate for Hispanics compared to white students and Hispanic college graduates receiving only 23\% of STEM degrees awarded in Texas (Froeschel and Normington, 2012). Earth and aerospace science-related industries are at the heart of the state's economy. Therefore, exposing precollege students to the geosciences is an important investment in human potential and makes sound economic sense.

Our strategy involved partnering with TERC, an independent, research-based organization located in Cambridge, MA, and dedicated to mathematics and science curricula development and teacher professional development; the Department of Petroleum and Geosystems Engineering (University of Texas at Austin); and the Texas Regional Collaboratives for Excellence in Science and Mathematics Teaching (TRC, at University of Texas at Austin), a state-funded, statewide network of science and mathematics educators. Our goal was to meet two key objectives:

(1) Provide minority-serving science teachers throughout Texas with high-quality geoscience professional development to enable them to transform their classrooms into environments where students are interested in, and motivated by, cutting-edge geoscience; and

(2) Prepare participating teachers to instruct Earth and Space Science, offered for the first time in the 20102011 academic year, so that their students could develop a deep understanding of the subject matter.

The TXESS Revolution served 177 science teachers by supporting them with the pedagogical, technological, and scientific tools to teach modern geoscience. The project succeeded in boosting the state's capacity to teach the new capstone course. TXESS Revolution teachers have directly impacted more than 29,000 students, of which $69.6 \%$ are nonwhite (Table I), by exposing students to the geosciences and planting the seeds for them to pursue geoscience as a field of study.

The scope of the project was ambitious, involving multiple partners from different institutions, the delivery of teacher professional development, and a research and evaluation component. In light of this complexity, we are preparing several articles to provide detailed information about the design and implementation of the project, as well as evaluation results. The purpose of this paper is to describe the key elements of program design that contributed to the success and achievements of the TXESS Revolution project. Important aspects of project implementation and evaluation that are necessary in understanding the main focus are also summarized in this article. The article concludes with a discussion of implications for the future and considers how the TXESS Revolution model of teacher professional development can be facilitated and sustained in Texas, as well as applied more broadly in other states.

\section{IMPLEMENTATION Project Team}

Key project personnel included a lead investigator and two coinvestigators, all scientists, who were responsible for professional development academy (PDA) content, served as instructors, prepared guest presenters, and developed the project Web site and the TXESS Revolution Virtual Café. A fourth scientist was instrumental in developing and teaching the summer field and petroleum institutes. A professional development coordinator at the TRC was tasked with participant recruiting and served as the liaison between local TRC chapter directors and project investigators. She also assisted with the delivery of professional development and activity development, especially in connection with their alignment to state standards. The team hired a part-time coordinator who took care of PDA logistics and Web site maintenance, served as the point of contact for teacher participants, and helped with the recruiting effort. The project evaluation team was composed of two faculty members with expertise in STEM education and educational psychology and two graduate students from the University of Texas Tyler. UTIG's information technology (IT) specialists provided technical assistance to the project.

\section{Participants}

Teachers were recruited for the TXESS Revolution primarily through our partnership with the TRC. This statewide network of $\mathrm{K}-16$ partnerships comprises 38 individual local chapters called collaboratives that partner with 22 institutions of higher education. The TRC has an exemplary track record of collaboration with the Texas Education Agency, the state's 20 regional education service centers (ESCs), school districts, and business partners to provide sustained science professional development. During the 4 -y project, each collaborative sent up to four teachers to participate in the TXESS Revolution program. In addition to the TRC network, we recruited and supported teachers from parts of the state that serve predominantly Hispanic (e.g., the Rio Grande Valley and southwest Texas) and African American students (e.g., Houston) through our connection to GeoFORCE Texas, an experiential outreach program at The University of Texas at Austin that prepares Texas high school students to become part of the geoscience workforce. Figure 1 shows the geographic distribution of TXESS Revolution teachers organized by the regions served by Texas's ESCs.

TXESS Revolution teachers were grouped into three 2-y cohorts, each with about 60 teachers: cohort A (2008-2009), cohort B (2008-2010), and cohort C (2009-2011). Teachers from different rural, suburban, and urban schools throughout Texas participated at each professional development experience with the same cohort and, through team learning and social activities, formed strong bonds that stretched across the state. Back home in their respective classrooms following the training academies and summer institutes in Austin, the teachers communicated and collaborated with 
TABLE I: Comparison of the ethnicity of TXESS revolution teachers and their students with demographic data for Texas teachers and students. ${ }^{1}$

\begin{tabular}{|c|c|c|c|c|c|c|}
\hline Teacher/Student Ethnicity & ${\text { African } \text { Amer. }^{2}}^{2}$ & Hispanic & White & Asian Amer. & Native Amer. & Other \\
\hline $\begin{array}{l}\text { TXESS Revolution teachers } \\
(N=177)\end{array}$ & $9.6 \%, 17$ & $18.1 \%, 32$ & $67.2 \%, 119$ & $3.4 \%, 6$ & $1.1 \%, 2$ & $0.6 \%, 1$ \\
\hline $\begin{array}{l}\text { All Texas teachers, Texas } \\
\text { HS science teachers }\end{array}$ & $9.5 \%, 9 \%$ & $22.5 \%, 14 \%$ & $66.4 \%, 74 \%$ & $1.6 \%, \mathrm{NA}$ & & \\
\hline $\begin{array}{l}\text { Students taught by TXESS } \\
\text { teachers }(N=29,333)\end{array}$ & $13.4 \%, 3,915$ & $53.1 \%, 15,565$ & $30.3 \%, 8,904$ & $2.1 \%, 629$ & $0.6 \%, 169$ & $0.5 \%, 151$ \\
\hline All Texas students & $14.0 \%$ & $48.6 \%$ & $33.3 \%$ & $4.1 \%$ & & \\
\hline
\end{tabular}

${ }^{1}$ Shown as percentages and the number of students, teachers, or both. HS = high school; NA = not applicable.

${ }^{2}$ Teachers who identified themselves as Afro-Caribbean and African are counted in the African American category.

Source: Texas Education Agency, 2010.

fellow TXESS Revolution teachers in other parts of the state and acted as resources and support for one another.

We adapted the TRC's train-the-trainer model for the project and encouraged participants to work in teams to turn their TXESS Revolution training around for 25 other teachers in their collaboratives and school districts. The teachers expanded this impact beyond their local area by giving workshops at the Conference for the Advancement of Science Teaching (the Science Teachers Association of Texas's annual meeting). Like ripples in a pond, the project documented that 177 TXESS Revolution teachers shared their training with 5,750 other teachers in $1,799 \mathrm{~h}$ of professional development. This number of 5,750 teachers is based on attendance data collected by the TRC at workshops

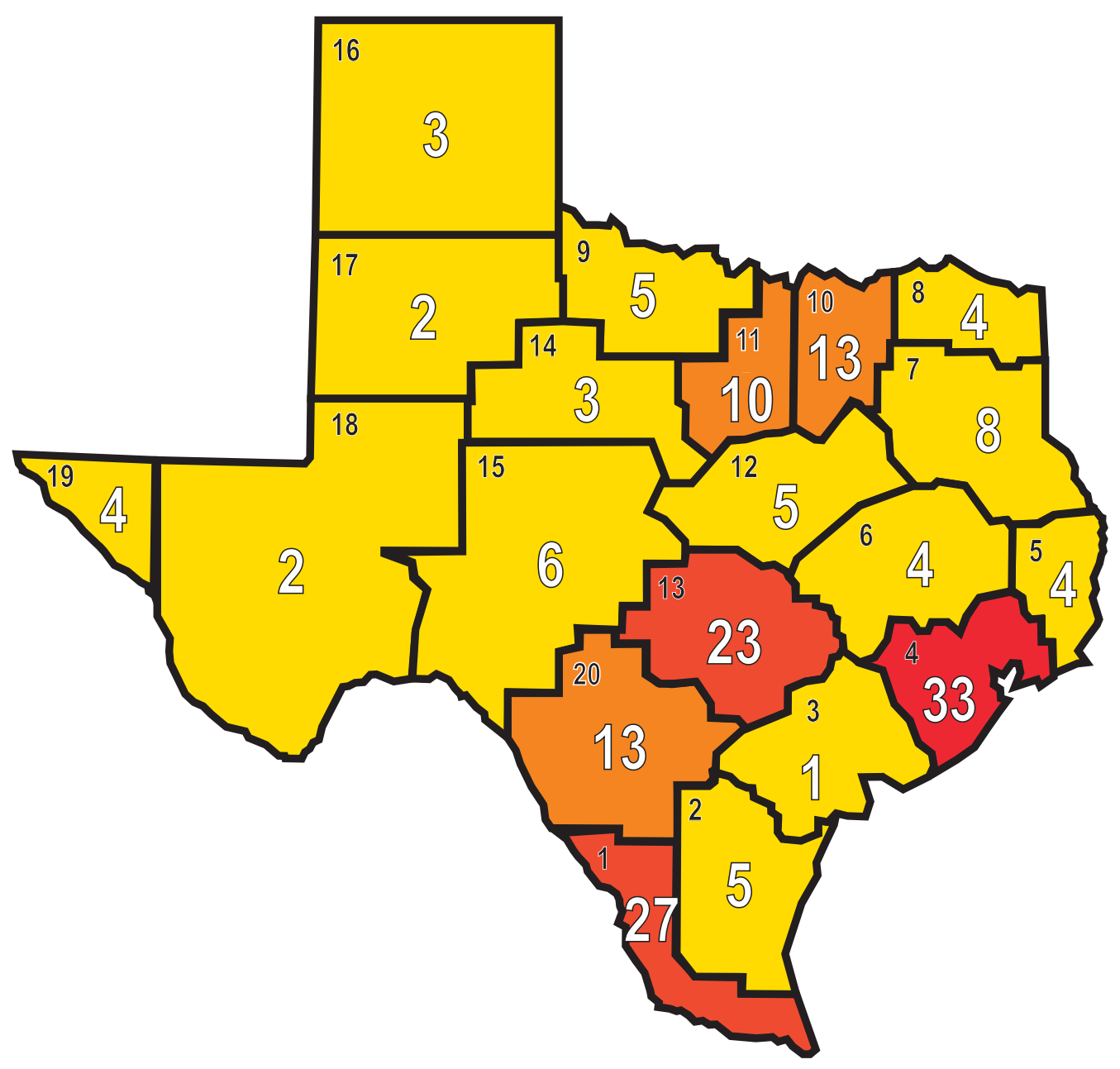

FIGURE 1: Map showing Texas ESC 1-20 and the geographic distribution of TXESS Revolution teachers. The smaller number is the ESC designation. The larger number indicates the number of teachers in each ESC region who participated in the TXESS Revolution. In addition, a community college educator from Michigan and an elementary teacher from Jamaica participated in the project. 
given by TXESS Revolution teachers. On average, each teacher reached 32 colleagues. Moreover, the partnership with the TRC contributed to the development of regional strength in Earth science education in Texas at all K-12 levels, an impact that extended beyond preparation for the new Earth and Space Science course. These outcomes support the contention that professional development is more likely to be successful when it involves the participation of teachers drawn together by their interest in the same subject area and who are from the same department, teach at the same grade level, or as in our case, participate in the same teacher networks (National Research Council [NRC], 2010). Anonymous teacher comments from surveys and focus groups revealed that teachers were enthusiastic about the TXESS Revolution professional development and motivated to provide project-related outreach to share the training with colleagues.

\section{Training}

The TXESS Revolution sought to help teachers build a solid foundation in Earth science through a professional development program rooted in an understanding of how people learn (Kolb, 1984; Bransford et al., 2000). The initiative followed established best practices set forth in the peer-reviewed literature (Loucks-Horsley et al., 1998; Kaser and Bourexis, 1999; Elmore, 2002; Guskey, 2002; Boyd et al., 2003; Borko, 2004; Darling-Hammond and Richardson, 2009; NRC, 2010). A standard we set for the professional development program was to provide up-to-date Earth science information through standards-aligned, guidedinquiry activities and lectures. These lectures were delivered by science experts in eight 2.5-d PDAs and 2-week-long summer institutes (based on a combination of five themes) offered over a 4-y period. The PDAs were modeled after a 2006 pilot project of Earth science professional development, Earth Science Revolution workshops, designed for TRC master teachers and Texas ESC science education specialists and funded by the Texas Education Agency.

The ability to apply scientific understanding to life situations in which science plays a role is considered an essential quality of scientific literacy by the 2006 Program for International Student Assessment (PISA), the system of international assessments that focuses on 15-year-olds' capabilities in reading literacy, mathematics literacy, and science literacy (Bybee et al., 2009). Approximately 400,000 randomly selected students participated in PISA 2006. The results revealed that the average science literacy of U.S. 15year-olds was 489, a score that is 11 points lower than the average score of students from 30 Organization for Economic Cooperation and Development (OECD) and 27 non-OECD nations (Bybee et al., 2009). We wanted to impart an understanding of the importance of science in society and public policy to our teachers to help them prepare both future geoscientists and scientifically literate citizens. Therefore, the TXESS Revolution learning activities and lectures were organized in themes (Table II) designed to help teachers and their students make connections between Earth science and their everyday lives.

At the end of their $2 \mathrm{y}$ of participation, teachers in each cohort summarized their TXESS Revolution accomplishments at a poster session to show examples of ways in which they used their new knowledge, either in the classroom or as outreach to their peers. Some displayed traditional or electronic portfolios they had created to chart progress and document achievements and their competence to teach Earth and space science, or to provide training in that subject to other teachers. Artifacts included a résumé; statement of teaching philosophy; reflective essay; images, video clips, or both of teaching; example lessons developed or adapted for classroom use; and field trips or research projects. Portfolios are a tried-and-true means of demonstrating achievement. By linking performance assessment to a product that had the potential to support career advancement, that is, demonstrating special qualification to teach a new Earth science course, we actively involved participants in the assessment process, allowing them to assume individual responsibility and ownership within that process (Palomba and Banta, 1999).

\section{Facilities}

The PDAs took place on campus at the University of Texas at Austin, where we had access to labs and state-ofthe-art seminar rooms with enough broadband to support teachers working on computers during the training. Teachers brought their own laptop computers. We were able to provide laptops for those who did not have them. At the start of each training session, IT specialists were on hand to troubleshoot issues that arose. Topic-related field trips and social events to allow informal contact between teachers and experts were integrated into the summer program.

\section{Curriculum}

Table II lists the TXESS Revolution PDAs and summer institutes; it also provides a brief summary of the content delivered. In addition to regularly scheduled PDAs, the project offered short training sessions by content experts on specific topics. Examples are a Google Earth workshop based on exercises developed by teacher and science consultant Steve Kluge (2009), an EarthScope teacher workshop offered in conjunction with the 2010 EarthScope national meeting, Global Learning and Observations to Benefit the Environment (GLOBE) training on TERC's EarthLabs Earth System Science curriculum module, and a workshop on the implementation of Water Exploration, the Texas Water Development Board's online water resource curriculum for high school students (Ellins et al., 2010a).

\section{Meeting the Needs of Our Teachers}

Teacher participants came from schools across the state that served urban, suburban, and rural districts with student populations that are largely Hispanic, African American, or both. Among Texas's K-12 student population, $14.0 \%$ are African American and 48.6\% are Hispanic (Texas Education Agency, 2012). Of Texas students, 59\% are classified as economically disadvantaged. Although the teachers in the program served a large number of minority students, the ethnic composition of our teacher pool (Table I) did not correspond to the ethnic composition of the of Texas's K-12 student population. It does, however, closely match the Texas teacher profiles. We understood the importance of having minority teachers who can serve as role models and worked with TRC to recruit minority teachers into the project. However, the small pool of minority science teachers from which to recruit in Texas, especially at the high school level, made it challenging and underscores the need to attract more minority teachers to science teaching. 
TABLE II: Listing and summary of topics covered in the PDAs and summer institutes.

PDA 1A (offered February 2008), Poking Holes Into the Planet, presented learning activities to demonstrate that science requires teamwork. Examples highlighted the science and technology involved in hydrocarbon exploration and two multinational programs, the IODP and ANDRILL.

PDA 2A (offered April 2008), Earth Outside In, introduced plate tectonics and seismology, using UTIG's plate tectonic reconstructions program called PLATES and UNAVCO and IRIS teaching materials. Activities integrated physics and mathematics into geoscience and involved participants in using cybertools and modeling.

PDAs 3A and 3B (offered October 2008), Earth is the Water Planet, focused on hydrology. Participants studied watersheds, aquifers, groundwater surface flow interactions, and droughts. Guests from the Texas Water Development Board presented information on the state water plan.

PDAs 4A and 4B (offered February 2009), Extremes, examined geohazards, the K-T Boundary event, and midocean ridge hydrothermal vents, using Ridge 2000/GLOBE FLEXE teaching materials. A panel of scientists who work in extreme environments or study extreme events shared their experiences with the teachers.

PDAs 5B and 5C (offered October 2009), Earth as a Habitable Planet, used Windows to the Universe learning activities to investigate planetary bodies of the solar system, the unique nature of our planet, and Earth's magnetic field and its importance in shielding life from harmful cosmic radiation. In this PDA, we emphasized the benefits of volcanism and examined corals as environmental indicators, using TERC's EarthLabs curriculum.

PDAs 6B and 6C (offered February 2010), Geologic Time, included paleontological, radiometric, and magnetostratigraphic techniques for putting Earth's history into a time framework. Participants practiced describing models of cores and applied stratigraphic principles to interpret geological history. They also learned about shorter-term cyclicity by looking at ice-core data.

PDA 7C (offered October 2010), Earth's Climate System, focused on the data behind climate science and the potential consequences of climate change, with activities that addressed key climate literacy principles. An assignment on climate literate decisions served as the framework for all PDA activities. Activities involved proxy data as paleoclimate indicators and the effects of climate change on the ancient Mayan civilization. We incorporated two EarthLabs investigations from the module on hurricanes to make the connection from the past to the present.

PDA 8C (offered February 2011), Humans at the Helm, focused on a small subset of ways in which humans interact with the planet: population, water, and energy. We used the example of Easter Island to set the stage for a discussion on world population, resources, and the mathematics of population growth. We looked at energy sources and food production, and we talked about sustainability. Finally, because science has been so often misrepresented in the media, we spoke via Skype with a scientist from the Woods Hole Oceanographic Institution whose data had been misrepresented to discuss how and why people manipulate scientific findings and how to spot it when it happens.

\section{Summer Institutes}

Each year, teachers were offered a 2-week summer institute that addressed one or two of the following themes:

Field Techniques (offered June 2008 and 2010), included up to 1 week of activities related to geological mapping, stratigraphic concepts, sedimentary geology, structural geology, and field geology. This institute culminated in a Central Texas field trip during which teachers were able to apply their newly acquired knowledge in field techniques, as well as smartphone apps for taking field measurements (strike and drip) and locating themselves on geological maps in the field (Universal Transverse Mercator coordinates versus latitude and longitude coordinates). This module was developed in collaboration with our partner, the Petroleum and Geosystems Engineering Department at the University of Texas at Austin.

Earth Science by Design (ESBD) (offered June 2008, 2009, and 2010), included up to 1 week of activities based on a program of professional development for teachers that was developed by TERC and the American Geological Institute with NSF funding (NSF Grant No. ESI-0138644). The program enables teachers to develop Earth science lessons or adapt existing ones for classroom use (McWilliams, 2003). The program is organized around a small set of "big ideas" that serve as the organizing framework for the teaching resources for the units that teachers developed. ESBD complemented the content and pedagogical approaches introduced in the PDAs.

Petroleum Science and Technology (offered June 2009), included 1 week of activities and instructional material that emphasized the applications of petroleum geology, drilling engineering, petrophysical properties, seismic data, well logs, and reservoir engineering in the petroleum industry. Teachers applied knowledge of Earth science gained from PDAs, for example, laboratory measurements of physical properties of rocks applied to reservoir engineering. Field trip components included a coal-fired plant and coal mine operated by Luminant near Dallas, Schlumberger Innovation Center in Houston, Wiess Energy Hall in Houston, and Ocean Star Museum in Galveston. This module was developed in collaboration with our partner, the Petroleum and Geosystems Engineering Department at the University of Texas at Austin.

Change Over Time (offered June 2010), included 1 week of a activities based on a new EarthLabs module focused on Earth's cryosphere that was designed to help learners build an understanding of change over time on multiple and embedded timescales. The module was composed of seven sequenced labs to allow learners to build on the knowledge and skills acquired in the previous labs. The labs begin with timescales that the students are familiar with, and in each successive investigation, the timescales overlap and extend to longer scales as different processes are examined.

Energy, Climate, and Water in the 21st Century (offered June 2011), included 2 weeks of activities and instructional material representing 1 week of content from the Petroleum Science and Technology module, with another week on the interrelationship of energy, climate, and water. Additional activities were related to water quality and consumption, water resource management, global energy resources, energy portfolios, and carbon sequestration. A field trip to Waco Wetlands, Waco Mammoth Site, and the Baylor University Center for Reservoir and Aquatic Systems Research in Waco augmented the in-class program.

Each PDA was composed of $24 \mathrm{~h}$ of contact. Participants were grouped in three cohorts designated as A, B, or C. Participants from all cohorts could apply to attend the summer institutes, which covered of a variety of themes and consisted of a total of $80 \mathrm{~h}$ of contact. 
Of the 177 teachers served by the project, 84 taught high school and 60 taught middle school. Although the project's target audience was teachers of grades 8-12, 15 participants were science education specialists in their school districts or at one of Texas's 20 ESCs, 7 were faculty at colleges or universities, and 12 were exceptional elementary teachers. One elementary teacher moved up to teach middle school science as a result of her participation in the TXESS Revolution. Teachers' experience teaching Earth science and level of preparation also varied. At the start of the project, most participants taught physics, chemistry. or biology and had limited knowledge of Earth science; 40 teachers taught Earth science. Teachers had bachelor's degrees in education or a science discipline other than geology; 74 had master's degrees, including 3 in geoscience, and 9 had doctoral degrees in STEM subjects, science education, or both.

Although teachers have some discretion concerning what and how they teach, they are ultimately responsible for implementing state educational standards and adhering to district policies. We understood that for our professional development program to be successful we would have to take this into consideration and emphasize content directly related to what our teachers were expected to teach. At the time of the start of the project in 2008, the standards for Earth and Space Science (Texas Essential Knowledge and Skills [TEKS]) had not yet been developed. However, once the TEKS were written and approved by the State Board of Education in 2009 (Texas Education Agency, 2009), we aligned our professional development and learning activities to be directly relevant to the new course to ensure that the project would have the desired impact.

\section{KEY ELEMENTS OF THE TXESS REVOLUTION MODEL}

The TXESS Revolution model was built on six principles, which guided the design of the program and contributed to its success: (1) model best practices in workshop presentations, (2) use authentic Earth science data and cybertechnology to teach up-to-date content, (3) provide ongoing training to cohorts of learners, (4) involve geoscience consortia and programs that can provide proven content for classrooms, (5) use ongoing evaluations to guide future workshops, and (6) provide opportunities for leadership development through participation in research and curriculum development projects.

\section{Modeling Best Practices in Workshop Presentations}

In our delivery of the professional development, we emphasized active learning, group participation, teamwork, and reflection. As the program designers, we selected the content, established the atmosphere for learning, guided the activities, set the pace, and encouraged discussion and reflection. We assumed multiple roles, ranging from expert to facilitator to coach to cheerleader. As experts, we used direct teaching to introduce topics and provide content necessary for learning to occur. As facilitators, we modeled an array of instructional strategies-guided inquiry, debate, role playing, and model building-and promoted independent Web-based research to help teachers acquire new knowledge and refine analytical and interpretive skills. As coaches and cheerleaders, we motivated teachers to work through challenging activities, helped them understand difficult concepts, and applauded their achievements. People learn in many ways, including through social interaction (Bransford et al., 2000). Therefore, we encouraged teachers to work collaboratively in teams to solve problems, share information, and engage in discussion. Finally, we set aside time for teachers to reflect on workshop delivery, content, and learning outcomes and to consider ways in which they could integrate new knowledge and skills into their own practice. We provided questions to help guide reflection. The process of reflection is an important element of teacher learning (Hoekstra and Korthagen, 2011). It promotes selfawareness, encouraging teachers to assess their own learning and explore how they teach. The small sampling of teacher reflections in Table III bears this out. Evaluation results show that through our approach and their experiences, teachers developed a more powerful understanding of Earth science and acquired the confidence and skills to teach the subject more effectively (Ellins et al., 2010b).

\section{Use of Authentic Earth Science Data and Cybertechnology to Teach Up-to-Date Earth Science Content}

Students' learning is related to the expertise of their teachers and the quality of instructional materials and instructional practices (Elmore, 2002; NRC, 2010; NRC, 2011). Our professional development delivery focused on engaging teachers in active learning that mirrors the way in which modern geoscientists conduct investigations. We avoided cookbook-style lesson plans with known outcomes and used instead learning activities that required the manipulation of real Earth science datasets derived from lab experiments, collected in the field, or available online, as well as a range of Web-based visualizations and interpretative tools.

Many of the instructional materials had been developed and tested previously by two of the authors with prior NSF and Texas Education Agency funding (Ellins and Olson, 2000; Ellins et al., 2002; Ellins and Olson, 2012). Additional high-quality materials that use real data came from TERC, the Science Education Resource Center (SERC), Antarctic Geological Drilling (ANDRILL), Ridge 2000, the Incorporated Research Institutions for Seismology (IRIS), UNAVCO, the Consortium for Ocean Leadership's Deep Earth Academy, and Windows to the Universe. In the workshops, teachers were asked to manipulate, evaluate, interpret, and discuss the data. For example, in an exercise about the fall of the Mayan civilization, teachers were given a large Excel file with 412 items of geochemical data tied to ages. They first graphed the geochemical data, which served as a proxy for the relative amount of precipitation (wet or dry) and then graphed population estimates for an ancient major Maya city center and drew conclusions about the observed relationship between population estimates and climate over a 1,000-y period (Ellins et al., 2011). In every workshop, Internet resources and laptops were widely used.

Evaluation results reveal that teachers liked our approach (Ellins et al., 2010b), particularly the use of Webbased tools like Google Earth and UNAVCO's EarthScope Voyager Jr. Teachers agreed that cyberlearning was exciting for their students, helped them develop new teaching strategies, and increased the level of technology comprehension for both students and teachers. Teacher anxiety stemming from a perceived lack of competence in the use of 
TABLE III: Timeline with number of participants from each cohort who attended each PDA.

\begin{tabular}{|c|c|c|c|c|c|c|c|}
\hline \multicolumn{3}{|l|}{2008} & \multicolumn{2}{|c|}{2009} & \multicolumn{2}{|c|}{2010} & \multirow{2}{*}{$\begin{array}{c}2011 \\
\text { Spring }\end{array}$} \\
\hline Spring & & Fall & Spring & Fall & Spring & Fall & \\
\hline PDA $1 \mathrm{~A}$ & PDA $2 A$ & PDA $3 A$ & PDA $4 \mathrm{~A}$ & & & & \\
\hline \multirow[t]{5}{*}{57} & 50 & 45 & 31 & & & & \\
\hline & & PDA 3B & PDA 4B & PDA 5B & PDA 6B & & \\
\hline & & 34 & 38 & 31 & 23 & & \\
\hline & & & & PDA 5C & PDA 6C & PDA 7C & PDA 8C \\
\hline & & & & 67 & 48 & 45 & 42 \\
\hline
\end{tabular}

The PDA designations $\mathrm{A}, \mathrm{B}$, and $\mathrm{C}$ refer to the cohorts.

computers is one factor that inhibits technology integration in the classroom (Brinkerhoff, 2006). As teachers' comfort with cyberlearning and social networking grew, we were able to introduce more challenging examples into our instructional practices. We also used cybertechnology to incorporate contributions from experts not physically present. For example, we inserted a YouTube video clip of the paleomagnetist on Integrated Ocean Drilling Program (IODP) expedition 318 (Wilkes Land) into a learning activity about the paleomagnetic polarity timescale. We also hosted Dr. Lloyd Kegwin of the Woods Hole Oceanographic Institution via Skype for a discussion with teacher participants about the misuse of paleoclimate data, which he had collected in the Northern Atlantic Ocean.

Our approach helped increase geoscience content knowledge, engendered an appreciation of how modern geoscience is done, and promoted the application of cybertechnology in learning, a key objective for the NSF (Borgman et al., 2008; Ryan and Eriksson, 2010). Specifically, we prepared teachers to teach for deep understanding of the subject matter; equipped them with a range of skills to guide their students to use authentic data, Web-based visualization, and virtual mapping tools and to access high-quality online geoscience educational resources; and exposed them to pedagogical approaches especially suited for teaching Earth science. To help teachers provide their students with learning experiences similar to their own experiences in the project, we assembled a collection of the best TXESS Revolution learning activities. This collection is freely available online at the TXESS Revolution Web site (TXESS Revolution, 2012b). The activities can be used independently or with our Blueprint for Instruction, which lays out a yearlong Earth and Space Science course that is aligned with the Earth and Space Science TEKS and the new national literacy framework documents. The blueprint includes links to educational materials, including those from other trusted sources that we used in the professional development program. These resources are accessible to any teacher who wants to implement Earth and space science instruction. As such, the TXESS Revolution teaching collection is an important legacy of the program.

\section{Ongoing Training to Cohorts of Learners}

The adoption of high-stakes testing in states throughout the U.S. to assess the efficacy of educational systems has led to an emphasis on teacher professional development as a mechanism for improving teacher performance and student achievement. Despite the undeniable value of professional development, the Texas Education Agency has limited funding and doesn't fund Earth science professional development for in-service teachers (Kenn Heydrick, personal communication, former director of science at the Texas Education Agency 2008-2011, 29 November 2011). Consequently, the Earth science professional development typically available consists of 1-d (or less) workshops with no planned follow-up. These fragmented efforts are insufficient because they cannot accommodate that meaningful learning is a nonlinear continuous process, with individual teachers responding differently and incorporating changes into their instructional practices at different rates (Kolb, 1984; Bransford et al., 2000; Borko, 2004; NRC, 2010). In contrast to these well-intentioned efforts, the TXESS Revolution provided opportunities for teachers to learn in an immersive environment over several days (duration) and to return multiple times for subsequent trainings (ongoing, extended).

\section{Duration}

The 2.5-d duration of each PDA and the weeklong summer institutes allowed teachers to focus on new content and gave them time for reflection on the information presented, how they could implement the learning activities in their own classrooms, and the quality of the training. Teacher reflections were logged on the project's networking space. These were visible only to participants in the same cohort, project investigators, and project evaluators. The immersive, multiday experience promoted continued dialogue among teachers, allowing them to share their ideas and explore one another's opinions. Most teachers were not from the Austin area and stayed together in the same hotel or dormitory facility. Consequently, conversations started during the day naturally spilled over into teachers' "free" time. Teachers typically work in self-contained classroom isolated from their colleagues (Elmore, 2002). This opportunity to connect with colleagues in a supportive environment contributed to gains in pedagogical content knowledge and self-efficacy documented by the project evaluation study. Indeed, survey results indicate that teachers enjoyed collaborating as a group and, early on in the project, expressed a desire for more time to work together and share ideas.

\section{Extended Professional Development}

Teachers committed to attending at least four training academies (96 h) over $2 \mathrm{y}$ and returned to the same venue for subsequent trainings. Summer institutes were optional and limited to 25 participants. Some researchers cite the 
TABLE IV: Timeline for summer institutes with number of participants who attended.

\begin{tabular}{|c|c|c|c|c|c|c|c|}
\hline \multicolumn{2}{|c|}{ June 2008} & \multicolumn{2}{|l|}{ June 2009} & \multicolumn{2}{|r|}{ June 2010} & \multicolumn{2}{|c|}{ June 2011} \\
\hline ESBD & Field Techniques & Petroleum Science & ESBD & ESBD & $\begin{array}{l}\text { Field Techniques and } \\
\text { Change Over Time }\end{array}$ & Petroleum Science & Energy, Climate, Water \\
\hline & 23 & \multicolumn{2}{|l|}{23} & \multicolumn{2}{|r|}{21} & \multicolumn{2}{|r|}{24} \\
\hline
\end{tabular}

Teachers from A, B, and C attended the summer institutes.

reluctance of school administrators to release teachers to attend ongoing professional development as an obstacle limiting the success of their programs (Sikora and Alexander, 2004). To avoid this problem and help ensure that teachers would be able to attend the minimum number of training academies. we required both teachers and their respective principals to sign a letter of commitment that clearly described the key elements of the TXESS Revolution program, time commitment, expectations of teacher participants, and expected benefits to individual teachers and their schools. In addition, we conducted the PDAs on a Thursday afternoon or evening, Friday, and Saturday. That timing made sure the teachers were not out of the classroom for an extended period.

Our approach proved effective. Nonetheless, some teachers did not complete the full 2-y program for reasons including a change of job or teaching assignment, feeling unprepared for the content level, and personal reasons, such as being affected by Hurricane Ike, which struck the Texas Gulf Coast in 2008. As spaces opened up, we admitted new teachers, although teachers who joined the project toward its end did not have the opportunity to participate in the complete 2-y professional development program.

Although teachers were expected to attend at least four different training academies, they could attend as many as eight training academies, four summer institutes, and several additional workshops given by other professional development providers, enabling them to accrue up to $553 \mathrm{~h}$ of contact for which they earned State Board for Educator Certification professional development credit. More than half of the participating teachers (96) completed all required hours (Table III). Many also attended the optional summer institutes (Table IV) and took advantage of additional professional development opportunities.

\section{Ongoing Professional Development}

Ongoing (meeting multiple times over an extended period) professional development encouraged more substantive engagement with the content and allowed teachers to develop organizational frameworks for learning new concepts and skills. In short, it gave teachers time to assimilate the information, integrate what they learned into their teaching, and share experiences with colleagues. At the start of the project, teachers admitted to feeling overwhelmed. Focus group discussions revealed that teachers quickly became accustomed to the rigor of the program and increasingly comfortable with the level of information being presented at each subsequent PDA. Evaluation results show that participants gained an appreciation for how information presented builds on previous knowledge, especially the technology training that is vital to working with Earth and space science data in the 21st century. The content of the TXESS Revolution PDAs was rigorous, and focus group participants reported that the summer institutes were especially helpful in elevating their comfort levels with the information being presented. The majority of the participants indicated that they felt increasingly more confident with the core content. Because of cost and space constraints, we could only accommodate a small subset of teachers (25) at the summer institutes.

Over time, teachers' increasing comfort with one another, project investigators, instructional materials, the physical environment, and the TXESS Revolution style of professional development had a positive impact on attitude and predisposition to learning. Teachers readily engaged project investigators and guest presenters in meaningful discussions about science. Our observations are consistent with the findings of researchers who have identified the best practices in professional development (Loucks-Horsely et al., 1998; Borko, 2004; Kedzior and Fitfield, 2004; DarlingHammond and Richardson, 2009; NRC, 2010). The TXESS Revolution experience provides clear evidence that a sustained professional development program comprising a series of multiday workshops offered over the course of $2 \mathrm{y}$ is one of the most important elements responsible for teachers' gains and the project's achievements (Ellins et al., 2010c; Ellins et al., 2010b).

We established the TXESS Revolution Virtual Café, a restricted networking space accessible only to TXESS Revolution teachers and key individuals involved in delivery of the professional development, to help teachers maintain connections with other TXESS Revolution teachers in their cohort and to allow them to share resources and distribute new information. All participants had access to a shared repertoire of communal resources (i.e., successful lessons, links to exemplary Earth and space science online resources, and personal blogs). The Virtual Café enjoyed limited success, however, being eclipsed by the meteoric rise of Facebook, which teachers preferred as a social networking tool to maintain connections with other teachers. The Virtual Café worked best for logging teachers' reflections (Table V) and targeted discussions during the PDAs and summer institutes, moderated by one of us-an observation that matches the findings of other researchers in the field (Wenger, 1998). Although TXESS Revolution teachers did not use our Virtual Café as we planned, they are networking and sharing ideas in cyberspace.

\section{Involvement of Geoscience Consortia and Programs}

Visiting scientists and distinguished speakers from organizations such as the National Association of Geoscience Teachers, IRIS, EarthScope, IODP, American Association of Petroleum Geologists, and Ridge 2000 presented material in special lectures on a variety of topics ranging from midocean ridge hydrothermal vent systems and climate change to the polar regions of Mars and the Chicxulub 


\title{
TABLE V: Selected examples of teacher reflections.
}

\begin{abstract}
I really enjoyed the presentation(s) today. The activities were not completely over my head-I will admit, I work/process a bit slower than most, so I didn't get most of the data finished-but I understood what was going on and got a clearer picture in my head about the movement of the plates during an earthquake. I will be more able to present the collection of this data to my students now that I know how it is done. I had a student just ask me this past week, "How do we know exactly how much the Atlantic Ocean is growing each year?" I gave my best explanation, but now I have the "right" answer (from an expert!). My understanding of the Juan De Fuca plate (from when I was studying for my degree in geology) was that it was basically rotating, counterclockwise, against the Pacific and North American plates... . Newer tools and further study have given me a better insight about what is really happening.
\end{abstract}

These activities will provide great rigor and relevance to the high school Earth science curriculum. They are challenging as well as interactive, however, some activities will need to be pared down or stretched over a period of several days. Unfortunately, we won't be able to do them all within the time frame allotted in the curriculum. However, I can see adapting them for other areas in the curriculum, in particular the study of oceans and the ocean floor environments.

I found this day extremely interesting. I learned a lot of new things, since I have not taken many Earth science courses in college, but I found that I was familiar with a lot of the things that were mentioned today during the workshop. I didn't know the specific names of nonconformities in the rock layers, but I was familiar with the fact that the oldest layers were on the bottom and the youngest were on top. I also found that ocean and wind currents facts were familiar to me from ecology classes that I took. I loved the hands-on activity where we put the fossil samples in order from youngest to oldest, because at first glance I didn't think I would have a clue how to do it. But as I thought about it I was very interested to see that even the untrained eye could pick up patterns.... I'm also excited to learn about new teaching strategies.

My classes will enjoy learning about the collapse of the Mayan civilization. Learning to analyze and interpret data will be challengingjust as it was initially for us to winnow out the critical concepts. I think that it would be best to do this activity after my classes have learned about core sampling in general; in fact, I think that I will have groups of students build cores that other students will have to interpret. This would be a great way for them to have a hands-on, minds-on connection with the data set given. With this connection, I think that the interpretive activity will be more meaningful for them.

This was a great, integrated activity. Since I work in a predominately Hispanic area, the students should really be interested in the culture and the topic. I thought the activity was a little tedious to read and follow (i.e., separating out directions from questions), so I may edit it before I use it in a class. I may also break it into segments considering our 48-minute classes. I am also thinking about using a water or flow table with it and including other labs (tree cookies, soil sampling and analysis) to make the process more real to them and hands on.

The activity was great. It was a good way to make the material relevant and include basic computer technology skills. I learned that there is a direct correlation between rainfall and aquifer recharge. Our water comes from Edward's aquifer, so it was interesting to see what its boundaries are and how it formed.

The most interesting thing I learned about tsunami waves this afternoon was that they actually slow down as they approach shore. It makes perfect sense, friction on the sea floor slowing it down, but from what we see on TV it always appears that they are coming in faster-I guess it's just a perception thing! The most frustrating thing for me today was trying to do the calculations using formulas that I am NOT familiar with and only having the instructions from the binder to go by. I am not that kind of learner-especially when it comes to math-so I felt increasingly more frustrated to the point that I didn't get the full impact of the final data. I hate it when I cannot participate in the final discussion because I have no idea what is being discussed or have no idea how the data/conclusions were obtained. Oh, well - there is plenty of information about tsunami waves that I can still share with my students—without using any of the calculations. Maybe I could just demonstrate how the waves slow down because of friction-friction is definitely a concept they understand!

impact event. In addition, scientists, faculty, and graduate students in the University of Texas Jackson School of Geosciences and the Petroleum and Geosystems Department gave presentations about their research. In all, 48 scientists gave lectures at the TXESS Revolution PDAs and summer institutes. These lectures were quite similar to talks the scientists might give when invited to visit another department, and they provided up-to-date content to help teachers keep abreast of recent developments in geoscience. Teachers quickly became comfortable interacting with guest presenters, and as their content knowledge and confidence increased, they asked more probing questions. Education specialists from geoscience consortia and programs also provided training on their curriculum during our regularly scheduled academies. Examples are (1) UNAVCO's learning activities in which learners work with authentic global positioning system data and time series plots and use the Web-based data viewing tool, EarthScope Jr., to visualize relationships among earthquakes, volcanoes, and plate boundaries; (2) Ridge 2000 From Local to Extreme Environ- ments (FLEXE) materials developed in collaboration with the GLOBE program (Goehring et al., 2012); and (3) ANDRILL's Antarctica's Climate Secrets collection. The TXESS Revolution benefited from the expertise of these volunteer scientists. Participation in the TXESS Revolution project helped them sharpen communication skills and improve their ability to convey the nature and value of their science to educators and the public. Geoscience consortia and programs benefited by achieving broader dissemination of their educational products and feedback on them from TXESS Revolution teachers.

\section{Ongoing Evaluation}

Evaluation was conducted throughout the project to ensure that the program met the needs of the target audience, was responsive to the feedback received from all project stakeholders, and was effective in achieving its goals, following methodologies described by Cook et al. (1979), McLaughlin and Jordan (1999), Palomba and Banta (1999), Shadish et al. (2002), Boulmetis and Dutwin (2005), Huber 
TABLE VI: TXESS Revolution participants' rating of the delivery and quality of PDA activities.

\begin{tabular}{|c|c|c|c|c|c|c|c|c|c|c|c|c|}
\hline PDA & $1 \mathrm{~A}$ & $2 \mathrm{~A}$ & $3 \mathrm{~A}$ & $3 B$ & $4 \mathrm{~A}$ & $4 \mathrm{~B}$ & $5 B$ & $5 \mathrm{C}$ & $6 B$ & $6 C$ & $7 \mathrm{C}$ & $8 \mathrm{C}$ \\
\hline Average rating $^{1}$ & 4.11 & 4.58 & 3.86 & 4.02 & 4.35 & 4.19 & 4.39 & 4.16 & 4.09 & 4.23 & 4.26 & 4.23 \\
\hline $\mathrm{SD}^{2}$ & 0.67 & 0.65 & 1.06 & 0.72 & 0.51 & 0.46 & 0.69 & 0.58 & 0.36 & 0.24 & 0.16 & 0.26 \\
\hline$n$ & 47 & 48 & 43 & 38 & 26 & 39 & 31 & 53 & 26 & 49 & 43 & 33 \\
\hline
\end{tabular}

${ }^{1}$ Activities are rated on a 5-point Likert scale, with responses ranging from 1 (low) to 5 (high). The results show mean response values ranging from 3.86 to 4.58. These average ratings indicate extremely positive feedback from the "Activity" survey reports and suggest that participants have a favorable attitude toward the TXESS Revolution professional development program.

${ }^{2} \mathrm{SD}=$ standard deviation.

and Hutchings (2005), and Walvoord (2004). A suite of instruments and surveys were used, along with focus group discussions, to document how teachers received the delivery of the PDA activities, the impressions and level of satisfaction of the teachers, and any changes in teachers' confidence level, content knowledge, and comfort in teaching the Earth and Space Science state standards. Evaluation was a part of every PDA and summer institute. We measured the gains made by the project participants using both qualitative and quantitative measures.

Ongoing evaluation allowed us to document teacher gains in confidence and content knowledge over the duration of the project and to identify when teachers were incorporating misconceptions in their teaching of Earth science. In addition, results of satisfaction surveys allowed us to change workshop timelines and methods of delivery in response to teacher feedback. A brief review of evaluation results follows. A thorough discussion will be presented in a separate paper.

We created some evaluation instruments specific to the project, but we also used two widely used instruments to be able to compare our results with other professional development. The Science Teaching Efficacy Belief Instrument (STEBI) (Riggs and Enochs, 1990) is a measure of teacher confidence in their preparation and ability to each science. The expectation is that increased confidence translates into more and better science teaching. The STEBI was administered to teachers in each cohort at the start of their participation and again, 2 y later, at the end to look for changes in teaching efficacy of participants. The STEBI is scored on a 5-point Likert scale, with responses ranging from strongly agree to strongly disagree. The theoretical midpoint is 2.5. While teachers' confidence in their ability to teach science increased (from 3.08 to 3.19), the change was not dramatic. This may be because we started with a group of confident teachers, and while they learned a lot, they also learned how much they still don't know. It would be interesting to have tested this at other points along the way. Perhaps it would have gone down and then back up.

We also used the Geoscience Concept Inventory (GCI) (Libarkin and Anderson, 2008), a multiple-choice assessment instrument for use in the Earth science classroom. The test consists of a pool of 73 questions that can be selected to create a customized 15-question GCI subtest for use in a course or workshop. These test items cover topics related to general physical geology concepts, as well as underlying science ideas that are integral to understanding the Earth. The pretest included all 73 questions. Postworkshop GCI tests contained only questions related to the content of the workshop. We correlated individual responses on content knowledge tests administered before and after each PDA with a unique number known only to the teacher; we recommended they use the last four digits of a well-used phone number. Here, the learning gains were obvious, with average pre- to posttests gains ranging from $12.6 \%$ (PDA 2A, Earth Outside In) to $37.5 \%$ (PDA 5B, Earth as a Habitable Planet). The average gain for all PDAs was 22.7\%.

These data-combined with learning gains tests for each workshop, teachers' rating of the delivery and quality of the PDAs and summer institutes (Tables VI and VII), and qualitative data on program satisfaction, and ideas for improvement documented in the focus groups-helped ensure that we were meeting the needs of teachers and our sponsors.

Specifically, quantitative research techniques were used to evaluate each major component of the PDAs and summer institutes. Participants were asked to use a 5-point Likert scale $(1=$ not at all; $5=$ very much) to rate each activity for each PDA and institute on the following three dimensions: (a) the activity was interesting, (b) the activity was applicable for implementation of guided inquiry, and (c) the activity was applicable for use of in-class technology. These three items were averaged for each activity, and across all activities involved in a given PDA, to form a composite quality index.

TABLE VII: TXESS Revolution participants' rating of the delivery and quality of summer institute activities, $2008-2011$.

\begin{tabular}{|l|c|c|c|c|c|c|c|}
\hline $\begin{array}{l}\text { Summer } \\
\text { Institute }\end{array}$ & $\begin{array}{c}\text { ESBD } \\
\mathbf{( 2 0 0 8 )}\end{array}$ & $\begin{array}{c}\text { Field } \\
\text { Techniques } \\
\mathbf{( 2 0 0 8 )}\end{array}$ & $\begin{array}{c}\text { Petroleum } \\
\text { Science } \\
\mathbf{( 2 0 0 9 )}\end{array}$ & $\begin{array}{c}\text { Field } \\
\text { Techniques } \\
\mathbf{( 2 0 1 0 )}\end{array}$ & $\begin{array}{c}\text { Change Over } \\
\text { Time (2010) }\end{array}$ & $\begin{array}{c}\text { Petroleum } \\
\text { Science } \\
(\mathbf{2 0 1 1})\end{array}$ & $\begin{array}{c}\text { Energy, Climate, } \\
\text { Water (2011) }\end{array}$ \\
\hline Average rating $^{1}$ & 4.24 & 4.11 & 4.82 & 4.84 & 4.80 & 4.08 & 4.50 \\
\hline SD & 0.76 & 0.67 & 0.37 & 0.65 & 0.36 & 0.24 & 0.03 \\
\hline$n^{2}$ & 19 & 19 & 23 & 15 & 15 & 22 & 22 \\
\hline
\end{tabular}

${ }^{1}$ Activities are rated on a 5-point Likert scale, with responses ranging from 1 (low) to 5 (high). The theoretical midpoint is 2.5 .

${ }^{2}$ The number of teachers who attended each of the summer institutes ranged between 20 and 23 . Not all attendees participated in the project evaluation surveys. 
Qualitative research techniques, in the form of unobtrusive interviews and focus groups, were used to gather feedback from PDA and summer institute participants. This feedback was used to shape the format and content of the PDAs that followed. Every group recognized that suggestions made by teachers to the evaluators were taken seriously and used to improve the professional development, content, delivery, and organization. Teachers expressed that they appreciated their thoughts and concerns being taken seriously.

\section{Opportunities for Leadership Development}

Evaluation results and focus groups reveal that TXESS Revolution teachers felt that the project helped them to gain the confidence to share what they have learned with other teachers by giving workshops to collaborative members and at conferences. Hilda Borrego, one of the handful of outstanding elementary teachers who participated in the program, organized workshops for more than 100 teachers in the Rio Grande Valley (predominantly Hispanic), pressing fellow TXESS Revolution teachers from the region into service to assist her. These efforts, summarized in a presentation at the 2011 Fall Meeting of the American Geophysical Union (AGU) (Borrego et al., 2011) have earned her recognition and an appointment to the University of Texas Pan American's science education department as an adjunct lecturer. Her TXESS Revolution experience has allowed her to become a middle school science teacher.

Some TXESS teachers became involved more deeply in ancillary research projects, such as the NSF-sponsored Seismic Investigation of Edge Driven Convection Associated with the Rio Grande Rift (SIEDCAR) project, IRIS' Seismographs in Schools program, and the Consortium for Ocean Leadership's Deep Earth Academy. Others worked on curriculum development projects led by investigators from the Texas Water Development Board, NSF, National Aeronautics and Space Administration, and TERC. Their involvement in TERC's EarthLabs project is ongoing. TXESS teachers delivered professional development to other teachers in workshops in 2012 and 2013 in Texas and Mississippi.

Teachers who participated in SIEDCAR helped to permit and install seismic stations in Texas and New Mexico in summer 2008 (Rockett et al., 2011). The IRIS-PASSCAL Instrument Center of the New Mexico Institute of Mining and Technology, hired two TXESS Revolution teachers from the SIEDCAR group to assist with the deployment of USArray instruments in West Texas in August 2008. USArray is part of the EarthScope experiment, a $15-y$ program to place a dense network of permanent and portable seismographs across the continental U.S. In addition, three teachers continue to work with SIEDCAR's principal investigator on a complementary study along Texas's Gulf Coast aimed at understanding continental evolution along a passive margin.

One exciting outcome is the participation of TXESS Revolution teachers in the IRIS Seismographs in Schools Project. There are 13 educational seismographs in the state distributed by IRIS through this program; 7 of these are operated by TXESS Revolution teachers, including some teachers who participated in the SIEDCAR research project. Teacher operators have received training from IRIS on how to set up and use their instruments. One teacher established an after-school seismology team for students in Eagle Pass, Texas (Brunt et al., 2011), which led to collaboration with a
UTIG scientist on a research project in Southwest Texas to examine an anomalous earthquake in 2010 in Alice, Texas, and to coauthorship on the resulting publication (Frohlich et al., 2012). This teacher's passion for Earth science will undoubtedly inspire students from this predominantly Hispanic region of Texas to consider careers in the geosciences (Fig. 2).

Three TXESS Revolution teachers have sailed as members of the science teams on the IODP drillship JOIDES Resolution on an expedition to investigate sea level variations recorded in the sediments offshore the South Island of New Zealand (November 2009-January 2010) and on the R/V Atlantic Explorer to measure particle fluxes in the deep Sargasso Sea in connection with the NSF-sponsored Oceanic Flux Program. In addition, the expedition team sampled plastic debris floating within the sargassum weed trapped in the North Atlantic gyre. One teacher, Jim Manley, reported on his experience and described how he applied the knowledge gained in his teaching at the 2011 Fall AGU Meeting (Manley et al., 2011).

Most science teachers never have the opportunity to do science. Participation in authentic research experiences enables teachers to strengthen their knowledge base, develop a deeper appreciation of the nature of science, hone their skills in sharing and critiquing scientific information, and participate as active members in the larger science community. Participation in authentic research and in curriculum development informs teachers' instructional practices. They incorporate new pedagogies and simulate the processes that scientists use to address research problems. As the examples discussed previously illustrate, involvement in authentic research also allows teachers to develop as Earth science education leaders at the state and national level and encourages them to share their experiences beyond the classroom at national geoscience conferences such as the AGU and Geological Society of America meetings (Brunt et al., 2011; Manley et al., 2011; Mote et al., 2011).

Several TXESS Revolution teachers have received recognition for their leadership in science education. We highlight three examples to showcase teachers' passion and creative involvement in science education. In 2009, Julie Pollard, a TXESS Revolution teacher from the Dallas area, received the Patty Holyfield Teaching Award, a \$5,000 award given biannually to a Texas teacher who demonstrates creativity in science teaching in grades $\mathrm{K}-12$. Michael Arratia, a STEM educator in the San Benito Consolidated Independent School District in the Rio Grande Valley of Texas, received a 2011 Society for Advancement of Chicanos and Native Americans in Science award for outstanding teaching and mentoring. In 2011, the National Association of Geosciences Teachers (NAGT) named Michael Brunt, a teacher from Eagle Pass, Texas, an Outstanding Earth Science Teacher for the Texas region.

\section{DISCUSSION \\ Implications for Earth Science Professional Development}

Although best practices for effective teacher professional development vary, depending on the target audience, there is consensus on several factors. Four of the key elements at the core of the TXESS Revolution program are consistent with best practices for professional development described 


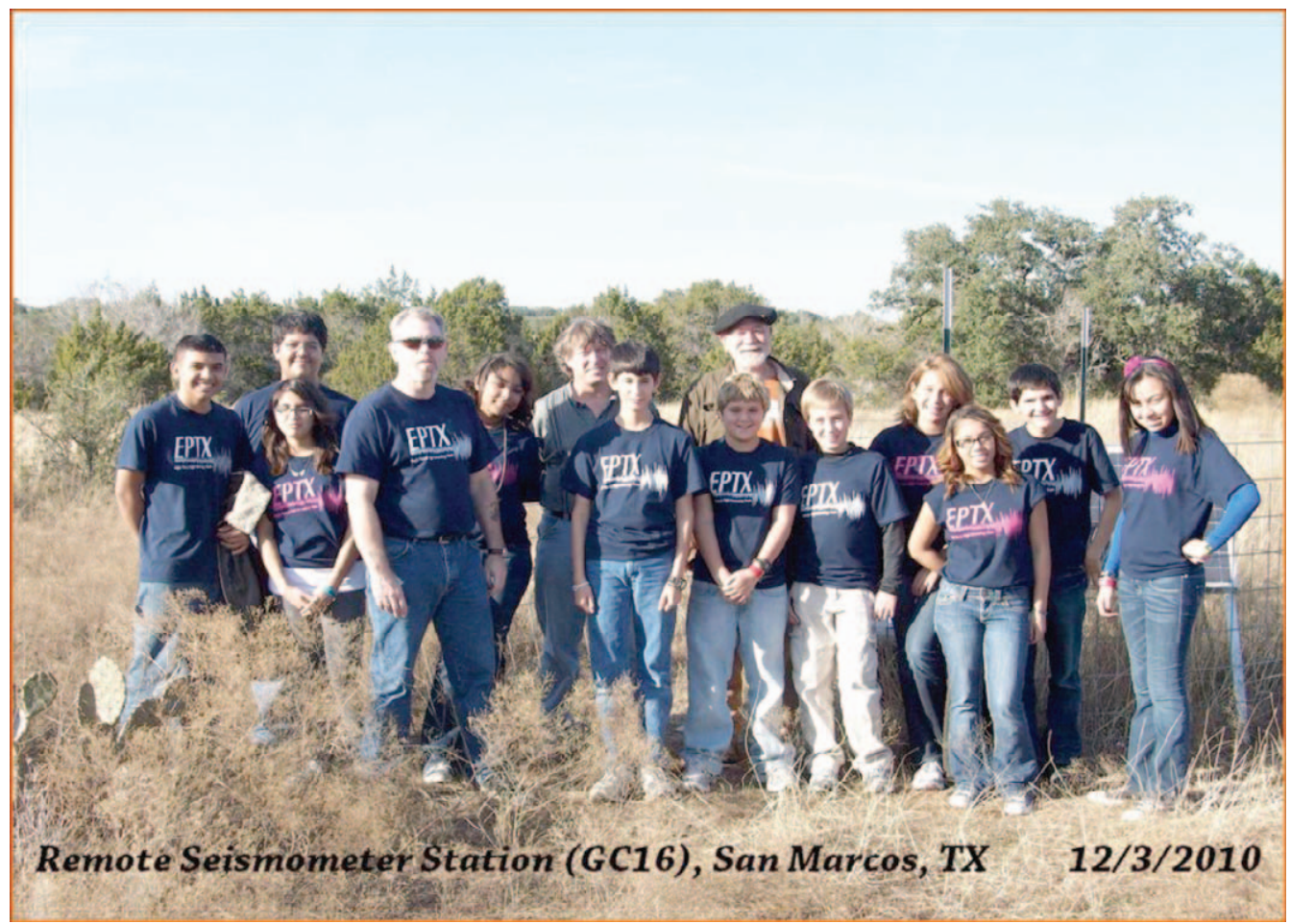

FIGURE 2: Eagle Pass teacher Michael Brunt with his school's seismology team. Jay Pulliam, professor of geophysics at Baylor University and lead SIEDCAR investigator, and David Boyd, STEM coach and physics instructor at Williams Preparatory School in Dallas, are in the background behind the students.

in the peer-reviewed literature. Researchers concur that content-specific professional development has a greater chance of success because knowledge of subject matter underpins good teaching (Loucks-Horsley et al., 1998; Elmore, 2002; Sikora and Alexander, 2004; Michaels et al., 2008; NRC, 2010). Professional development that promotes active learning, fosters group collaboration, and provides opportunities for teacher reflection leads to greater improvement in teachers' knowledge, skills, and attitude (LoucksHorsley et al., 1998; Boyd et al., 2003; Darling-Hammond et al., 2009). Sustained professional development experiences of longer duration, that is, more than once and of duration longer than $1 \mathrm{~d}$, offer more opportunities for learning new content, collaboration, and reflection (Kedzior and Fitfield, 2004; Sikora and Alexander, 2004; Darling-Hammond et al., 2009). Participation of teachers from the same school, subject area, or both promotes more active learning. In addition to these factors, we identified additional elements that establish the context for successful Earth science teacher professional development. These are the use of cyberlearning, the involvement of scientists and science education specialists from geoscience consortia and programs, and the emphasis on leadership opportunities.

Once back in their classrooms, TXESS Revolution teachers have to contend with the realities of the environment in which they teach, including the students they teach, physical infrastructure, and cultural atmosphere. Without organizational support, we recognize that some may be challenged to continue to improve their practice and adapt the curriculum resources to fit the courses that they teach. A logical next step is for us to find ways in which we can sustain the capacity created by the TXESS Revolution to support teachers' practice and skills in the classroom. This will require collaboration with experts trained to provide guidance to practicing teachers as they hone new pedagogical skills, master content, and adapt new curriculum and content knowledge to fit their schools and students. To that end, we are working through the newly created Diversity and Innovation for Geosciences in Texas network to connect TXESS Revolution teachers with geoscientists and science education faculty at institutions of higher education in their respective regions of Texas. The TXESS Revolution project has also forged an alliance with the Jackson School of Geoscience's Friends and Alumni Network to partner TXESS Revolution teachers with alumni volunteers who will serve as content experts and offer guidance on geoscience careers. Finally, an instructional blueprint designed to serve as a coherent framework for teachers to follow as they teach a 1-y Earth and Space Science course (approximately 30 weeks) resides on the TXESS Revolution Web site (TXESS Revolution, 2012a). It is organized on the eight large themes in Earth system science that were presented in the TXESS Revolution professional development program and has links to preexisting, exemplary learning activities and resources. A new NSF project will use the TXESS Revolution blueprint to guide the development of five additional blueprints for teaching Earth science, which will be available on the SERC Web site.

\section{Challenges}

One of the first challenges we faced was recruiting our target number of teachers for the initial cohort. Our initial strategy for recruiting teachers was our partnership with the 
TRC. However, several factors conspired to reduce TRC's impact in recruiting. One factor arose from miscommunication in the proposal writing stage, which resulted in our two organizations having different expectations of how the teachers would be targeted. Ultimately, we had to find middle ground between the two agencies, which resulted in fewer TRC participants than anticipated. We then began an aggressive recruiting campaign to fill our cohorts. We took the following steps:

- Exhibited and presented workshops at state and regional science educator meetings

- Hired a teacher with whom we had worked before to recruit colleagues in his region

- Used online state databases to locate and target specific districts with high concentrations of minority and minority-serving teachers, and invited them to apply

- Partnered with GeoFORCE Texas to tap into their teacher network

A second factor affecting recruitment is that the project began before the state standards for the Earth and Space Science course had been developed. Teachers were uncertain about the nature and requirements of the new high school course and whether it would be adopted by their schools. To counter this, we created a flyer that teachers could use to educate their principals and superintendents and to persuade them to offer the course. The flyer covered why the course is interesting and relevant and the facilities and equipment the school would need to offer it.

Despite the important advantages of multiple partners in a large-scale project such as the TXESS Revolution, another challenge was merging the differing cultures of partner organizations. Each partner's mission and culture influenced approaches to project management and communication, as well as expectations for participants. Some of our partners had dissimilar funding structures, complicating the allocation of project resources. Finally, partners' priorities reflected those of their primary sponsors and, in the case of state sponsorship, were influenced by the shifting political realities of the time. These challenges will always exist where multiple organizations are involved. The following strategies helped resolve these issues:

- Regular meetings to promote clear communication and collegiality

- Recognition among partners that differences will exist and compromises must be made

- Flexibility and willingness to make changes when necessary

- Respect for each partners' strengths and willingness to concede control when appropriate

The project remained on track and was successful because all partners remained united behind the common goal of strengthening Earth science education in Texas.

In Texas, there are still challenges to overcome. During 2010-2011, the first year that Earth and Space Science was taught, only 13,367 students took the course (Perry Weirich, personal communication, Texas Education Agency, 9 March 2012). In comparison, 226,357 students took physics, 328,050 took chemistry, and 391,874 took biology
(Texas Education Agency, 2011). The Texas Education Agency has promoted Earth and space science as the natural complement to physics, chemistry, and biology, which are mandatory courses. However, many school districts have not yet included Earth and space science as a viable ongoing course (Heydrick, personal communication, 2011). While the number of students who took Earth and Space Science the first year the course was offered is disappointing, 107,191 Texas high school students took an Earth science course (Aquatic Science, Environmental Science, Astronomy, or Environmental Systems) that year, indicating strong interest in the field. Therefore, we expect the number of students enrolled in Earth and Space Science to steadily increase in time. Effective in-service teacher professional development programs that are sustained over the long term can have an important impact on whether Earth and space science is taught as a rigorous course in Texas and whether it remains an option to satisfy the required fourth science course under the state's recommended and distinguished high school graduation plans.

We cannot ignore the larger challenge that faces the entire Earth science community. The brightest high school students are told they must take advanced placement (AP) classes to be competitive for elite colleges, and there is no geoscience AP class. As long as this situation remains, courses like Earth and Space Science in Texas will struggle to find an audience, and the brightest minds in the nation will be unexposed to high-level Earth science before college.

\section{CONCLUSION}

The TXESS Revolution has boosted the capacity of Texas schools to offer the capstone Earth and Space Science course by providing a pool of highly qualified Earth science teachers. In this paper, we have described the key characteristics of the TXESS Revolution project that make it an effective instrument of instructional improvement in the K-12 Earth science education. At a workshop in June 2012 in Austin, we shared our model with faculty from other Texas colleges and universities, science education specialists, and TXESS Revolution alumni interested in providing TXESS Revolution-style professional development in their regions. As a part of the summer institutes, we were able to introduce the participating Department of Petroleum and Geosystems Engineering faculty to the latest in teaching pedagogy. Their involvement with the TXESS Revolution inspired a new lab-based, freshman-level introductory course titled Engineering, Energy and the Environment, which includes many of the activities created by its faculty for the TXESS Revolution program and an education, training, and outreach program at the Center for Petroleum and Geosystems Engineering.

An important outcome of the train-the-trainer model that we employed is the delivery of this professional development to teachers throughout Texas, strengthening Earth science education throughout the state at all $\mathrm{K}-12$ levels, an impact that extends beyond preparation Earth and space science. Analysis of the demographic data that we collected clearly shows that the TXESS Revolution succeeded in reaching minority students in Texas through the teachers in the project. In time, our efforts will increase the participation of minorities in the geosciences and, 
ultimately, the number of geoscience bachelor's degrees awarded to minorities. This influx of minorities with degrees in the geosciences will lay the groundwork for Earth science-related industries to recruit qualified workers from within Texas, a state in which Earth sciencerelated industries are vital to the economy. In testimony before the Texas State Board of Education on 14 September 2006, Dan Barstow of TERC underscored the economic importance of Earth and space science to Texas and declared that, "An Earth-literate work force is a business mandate for Texas" (Barstow, 2006).

\section{Acknowledgments}

NSF's Opportunities for Enhancing Diversity in the Geosciences program funded the TXESS Revolution under Grant No. 0703687. The Shell Oil Company Foundation, through a grant to the TRC, supported the participation of TRC teachers in the project. The University of Texas Jackson School of Geosciences provided support for the participation of teachers who were not part of the TRC network. The TXESS Revolution used curriculum materials developed with prior NSF funding under NSF Geoscience Education Grant No. 0224501 and NSF Cross Cutting Programs Grant No. 0139347. The TXESS Revolution is the result of collaboration with many formal and informal partners. We recognize the intellectual contributions and participation of Department of Petroleum and Geosystems Engineering faculty P. Bommer, S. Bryant, L. Lake, and C. Torres-Verdin and of TERC researchers C. McAuliffe and $\mathrm{H}$. McWilliams. We also appreciate the contributions of ANDRILL, the Deep Earth Academy, EarthScope, GLOBE, IRIS, NAGT, Ridge 2000, the Texas Water Development Board, UNAVCO, and Steve Kluge. We are especially grateful to our project coordinator, Elizabeth Polito, for her invaluable assistance. Finally, we thank UTIG Associate Director Cliff Frohlich for his comments on this paper.

\section{REFERENCES}

American Geosciences Institute. 2011. U.S. geoscience today and in the next decade. Available at http://www.agiweb.org/pubs/ pubdetail.html?item $=800821$ (accessed 14 March 2012).

Barstow, D. 2006. Testimony before the Texas State Board of Education, 14 September 2006.

Barstow, D., and Geary, E. 2002. Blueprint for change: Report from the National Conference on the Revolution in Earth and Space Science Education. Cambridge, MA: TERC, p. 100. Available at http://www.earthscienceedrevolution.org (accessed 1 March 2010).

Borgman, C., Abelson, H., Dirks, L., Johnson, R., Koedinger, K.R., Linn, M.C., Lynch, C.A., Oblinger, D.G., Pea, R.D., Salen, K., Smith, M.S., and Szalay, A. 2008. Fostering learning in a networked world: The cyberlearning opportunity and challenge. Report of the NSF Task Force on Cyberlearning NSF08204, p. 64.

Borko, H. 2004. Professional development and teacher learning: Mapping the terrain. Educational Researcher, 33(8):3-15.

Borrego, H., and Ellins, K. 2011. Providing elementary teachers in South Texas with professional development to improve Earth science instruction. Presented at the 2011 Fall Meeting of the American Geophysical Union, San Francisco, CA, 5-9 December.

Boulmetis, J., and Dutwin, P. 2005. The ABCs of evaluation:
Timeless techniques for program and project managers, 2nd ed. San Francisco, CA: Jossey-Bass.

Boyd, S.E., Banilower, E.R., Pasley, J.D., and Weiss, I.R. 2003. Progress and pitfalls: A cross-site look at local systemic change through teacher enhancement. Available at http://www. horizon-research.com/reports/2003/progress_and_pitfalls.php (accessed 3 October 2006).

Bransford, J.D., Brown, A.L., and Cocking, R.R., eds. 2000. How people learn: Brain, mind, experience, and school. Washington, DC: National Academy Press, p. 384.

Brinkerhoff, J. 2006. Effects of a long-duration, professional development academy on technology skills, computer selfefficacy, and technology integration beliefs and practices. Journal of Research on Technology in Education, 39(1):22-43.

Brunt, M.R., Ellins, K.K., and Frohlich, C.A. 2011. Eagle Pass Jr. High seismology team: Strategies for engaging middle school "at-risk" students in authentic research, Abstract ED33C-03. Presented at the 2011 Fall Meeting of the American Geophysical Union, San Francisco, CA, 5-9 December.

Bybee, R., McCrae, B., and Laurie, R. 2009. PISA 2006: An assessment of scientific literacy. Journal of Research in Science Teaching, 46(8):865-883.

Cook, T.D., and Campbell, D.T. 1979. Quasi-experimentation: Design and analysis for field settings. Boston, MA: Houghton Mifflin.

Darling-Hammond, L., and Richardson, N. 2009. Teacher learning: What matters? Educational Leadership, 66(5):46-53.

Ellins, K.K., McCall, L.R., Amos, S., McGowan, R.F., Mote, A., Negrito, K., Paloski, B., Ryan, C., and Cameron, B. 2010a. Water exploration: An online high school water resources program, Abstract ED 23B-0717. Presented at 2010 Fall Meeting of the American Geophysical Union, San Francisco, CA, 13-17 December.

Ellins, K.K., and Olson, H.C. 2000. From Texas to Antarctica: A voyage of intrigue and discovery. Austin, TX: UTIG. p. 113.

Ellins, K.K., and Olson, H.C. 2012. Enhancing geoscience education within a minority-serving teacher population. Journal of Geoscience Education, 60(1):34-44, doi:10.5408/11-229.1.

Ellins, K.K., Olson, H.C., Snow, E., Odell, M., Stocks, E., and Willis, M. 2010b. The impact of the Texas Earth and Space Science (TXESS) Revolution. Geological Society of America Abstracts with Programs, 42(5), Paper No. T43-133-1.

Ellins, K.K., Olson, H.C., Snow, E., Peart, L., and Goehring, L. 2010c. Geoscience professional development for minorityserving K-12 science educators: The TXESS Revolution. Eos, 91(26), Abstract ED43A-01.

Ellins, K.K., Rodgers, J., and Cano, J. 2011. Climate and civilization-The Maya example, TXESS Revolution. Available at http://www.txessrevolution.org/MayaExampleAssessments (accessed 19 March 2013).

Elmore, R.F. 2002. Bridging the gap between standards and achievement: The imperative for professional development in education. Available at http://www.shankerinstitute.org/ Downloads/Bridging_Gap.pdf (accessed 2 January 2012).

Froeschle, R.C., and Normington, M. 2012. Working Texas style: Think globally, plan regionally. Austin, TX: Texas Workforce Commission, p. 152. Available at http://63.88.32.17/Programs/ 2009ReportsAndPlans/Economic_Analysis_Reports/TXWorkingStyle.htm (accessed 16 April 2012).

Frohlich, C., Glidewell, J., and Brunt, M. 2012. Location and felt reports for the 25 April $2010 \mathrm{~m}_{\mathrm{bLG}} 3.9$ earthquake near Alice, Texas: Was it induced by petroleum production? Bulletin of the Seismological Society of America, 102(2):457-466.

Goehring, E., Robigou, V., and Ellins, K. 2012. Bringing mid-ocean ridge discoveries to audiences far and wide: Emerging trends for the next generation. Oceanography, 25(1):286-298. Available at http://dx.doi.org/10.5670/oceanog. 2012.28 (accessed 1 March 2012). 
Guskey, T.R. 2002. Professional development and teacher change. Teachers and Teaching: Theory and Practice, 8(3/4):381-391.

Hallar, A.G., McCubbin, I.B., Hallar, B., Levine, R., Stockwell, W.R., Lopez, J.P., and Wright, J.M. 2010. Science in the mountains. Journal of Geoscience Education, 58(2):95-100.

Hoekstra, A., and Korthagen, F. 2011. Teacher learning in a context of educational change: Informal learning versus systematically supported learning. Journal of Teacher Education, 62(1):76-92.

Huber, M.T., and Hutchings, P. 2005. The advancement of learning: Building the teaching commons. San Francisco, CA: JosseyBass, p. 187.

Kaser, J.S., and Bourexis, P.S. 1999. Enhancing program quality in science and mathematics. Thousand Oaks, CA: Corwin Press, p. 222.

Kedzior, M. and Fitfield, S. 2004. Teacher professional development. University of Delaware Educational Research \& Development Center Education Policy Brief, 15. Available at http://www. rdc.udel.edu (accessed 10 January 2012).

Kluge, S. 2009. Encounter Earth: Interactive geoscience explorations. New York: Prentice Hall, p. 72.

Kolb, D.A. 1984. Experiential learning: Experience as the source of learning and development. Englewood Cliffs, NJ: Prentice Hall, p. 256.

Libarkin, J., and Anderson, S.W. 2008. Development of the geoscience concept inventory. Proceedings of the National STEM Assessment Conference, Washington, DC, 19-21 October 2006, p. 148-158.

Loucks-Horsley, S., Hewson, P. Love, N., and Stiles, K.E. 1998. Designing professional development for teachers of science and mathematics. Thousand Oaks, CA: Corwin Press, p. 325.

Manley, J., Ellins, K.K., and Conte, M.H. 2011. Engaging middle school students in authentic research based on a summer research cruise, Abstract ED33C-07. Presented at the 2011 Fall Meeting of the American Geophysical Union, San Francisco, CA, 5-9 December.

McLaughlin, J.A., and Jordan, G.B. 1999. Logic models: A tool for telling your program performance story. Evaluation and Program Planning, 22:65-72.

McWilliams, H. 2003. Teachers as educational designers. Hands On! 26(2):4-7. Available at http://www.esbd.org/homepage/ esbd_article.pdf (accessed 15 March 2012).

Michaels, S., Shouse, A.W., and Schweingruber, H.A. 2008. Ready, set, science: Putting research to work in $\mathrm{K}-8$ science classrooms. Washington, DC: National Academy Press, p. 197.

Mote, A.S., Ellins, K.K., and Haddad, N. 2011. The EarthLabs approach to curriculum and professional development: Earth science education in the 21st century, Abstract ED34B-08. Presented at the 2011 Fall Meeting of the American Geophysical Union, San Francisco, CA, 5-9 December.

National Research Council (NRC). 1996. National science education standards. Washington, DC: National Academy Press, p. 262.

NRC. 2010. Exploring the intersection of science education and 21st century skills. Washington, DC: National Academy Press, p. 134.

NRC. 2011. A framework for K-12 science education: Practices, cross-cutting concepts, and core ideas (prepublication copy). Washington, DC: National Academy Press, p. 320.

National Science Foundation (NSF). 2010. Science and engineering degrees by race/ethnicity of recipients: 1997-2006, detailed statistical tables. NSF Division of Science Resources Statistics Report 10-300. Available at http://www.nsf.gov/statistics/ nsf10300/ (accessed 25 March 2011).
O'Connell, S., and Holmes, M.A. 2011. Obstacles to the recruitment of minorities into the geosciences: A call to action. GSA Today, 21(6):52-54, doi:10.1130/G105GW.1.

Palomba, C.A., and Banta, T.W. 1999. Assessment essentials: Planning, implementing and improving assessment in higher education. San Francisco, CA: Jossey-Bass, p. 304.

Riggs, I.M., and Enochs, L.G. 1990. Toward the development of an elementary teacher's science teaching efficacy belief instrument. Science Education, 74(6):625-637, doi:10.1002/sce. 3730740605.

Rockett, C.V., Pulliam, J., Xia, Y., and Grand, S.P. 2011. Seismic tomographic imaging of an upper mantle anomaly beneath the Rio Grande Rift: Results from SIEDCAR. Presented at the EarthScope National Meeting, Austin, TX, 18 May 2011.

Roy, E.C., Jr. 2002. Earth science in Texas: A progress report. Geotimes. Available at http://www.geotimes.org/sept02/ feature_texas.html (accessed 21 January 2013).

Ryan, J.G., and Eriksson, S. 2010. Planning the Future of GeoCyberEducation. Report From a Workshop Held at the Hilton Arlington and Towers, Arlington, VA, 6-8 January 2010.

Shadish, W.R., Cook, T.D., and Campbell, D.T. 2002. Experimental and quasi-experimental designs for generalized causal inference. Boston, MA: Houghton Mifflin, p. 623.

Sikora, D., and Alexander, K.L. 2004. Creating meaningful professional development for new FACS teachers through collaborative action research. Journal of Family and Consumer Sciences Education, 22(2):47-51.

Texas Education Agency. 2003. Report of the Earth Science Task Force, June 2003. Available at http://www.tea.state.tx.us/sboe/ schedule/1103/earthsciatt1.html (accessed 5 September 2004).

Texas Education Agency. 2009. Texas administrative code (TAC), Title 19, Part II, Chapter 112. Texas Essential Knowledge and Skills for Science. Available at http://ritter.tea.state.tx.us/rules/ tac/chapter112/index.html (accessed 27 February 2010).

Texas Education Agency. 2010. Pocket edition: 2009-10 Texas public school statistics. Available at http://ritter.tea.state.tx.us/ perfreport/pocked/2010/pocked0910.pdf (accessed 24 April 2012).

Texas Education Agency. 2011. Final recommendations of the Commissioner of Education regarding instructional materials offered for adoption under the request for supplemental science materials, July 22, 2011. Available at http://www.tea. state.tx.us/news_release.aspx?id=2147501735 (accessed 6 October 2011).

TXESS Revolution. 2012a. Blueprints for instruction. Available at http://www.txessrevolution.org/About_Blueprints (accessed 19 March 2013).

TXESS Revolution. 2012b. Welcome to the Texas Earth and Space Science (TXESS) Revolution Website! Available at http://www. txessrevolution.org/ (accessed 19 March 2013).

U.S. Census Bureau. 2010. State and county quick facts. Available at http://quickfacts.census.gov/qfd/states/48/4841464.html (accessed 16 April 2012).

Walvoord, B. E. 2004. Assessment clear and simple: A practical guide for institutions, departments, and general education. San Francisco, CA: Jossey-Bass.

Wenger, E. 1998. Communities of practice: Learning as social system. Systems Thinker. Available at http://www.co-i-l.com/ coil/knowledge-garden/cop/lss.shtml (accessed 3 October 2006). 